\title{
A CLINICAL CASE OF LOSS OF THE UPPER LATERAL INCISORS AS A RESULT OF CANINES IMPACTION
}

\author{
Hristina Arnautska, Gergana Ivanova. \\ Department of Prosthetic Dental Medicine and Orthodontics, Faculty of Dental \\ Medicine, Medical University - Varna, Bulgaria
}

\begin{abstract}
:
The resorption of the lateral incisors after ectopic eruption of the permanent canines is one of the most common complications and may be detected in all cases of seriously altered route of eruption. The case presented is of a 10-year old boy with permanent dentition and extracted upper lateral incisors as a result of a severe degree of resorption of their roots due to improper eruption of the canines. This article aims at establishing that early detection and prompt preventive measures will lead to avoiding the critical complications arising out of the impacted canines and will preserve the morphological and functional integrity of the incisors and the dentition.
\end{abstract}

Keywords: impacted canines, incisors resorbtion, orthodontics treatment

\section{INTRODUCTION}

A number of authors have ascertained that there exists a strong dependence between impacted canines, the contact with their adjacent teeth and the root resorption of the incisors $(1,3,6)$. These authors have also established that the frequency of root resorption of the lateral incisors is $12.5 \%$. The treatment of impacted canines is complex and prolonged. However, the final result is dubious, in particular in the cases of palatal impaction of canines.

Ericson and Kurol $(3,4)$ assume that the resorption of the lateral incisors after ectopic eruption of the permanent canines is the most common complication and may be detected in all cases of considerably altered route of canine eruption. It is most commonly seen in the lateral incisors in $38 \%$, and less frequently in the central incisors - in $9 \%$ of the cases. The apical and median third of the root are most commonly affected - in about $65 \%(2,4,5)$. Thanks to CAT, nowadays we can detect even minimal resorption fields on the incisor roots and establish that in almost $50 \%$ of the cases with impacted canines.

Ericson and Kurol $(3,4)$ group the severity of resorption of the lateral incisor in 4 degrees:

- no resorption - intact surface;

- slight resorption - up to the middle of the depth of the root dentin;

- moderate resorption - affects more than half of the depth of the root dentin

- severe resorption - reaches the root pulp.

The aim of the case presented is to demonstrate the severe complication due to the improper eruption and the impaction of the canines in the upper jaw, related to the loss of the two upper lateral incisors. By means of proper detection and prompt prevention of the modified eruption this can be avoided.

\section{TREATMENT OF THE CLINICAL CASE:}

The case presented involves a 10-year old boy who has lost his upper lateral incisors due to severe resorption of their roots by the palatally impacted upper canines (fig. 1). A slight degree of resorption of the root of the two upper central incisors is observed.

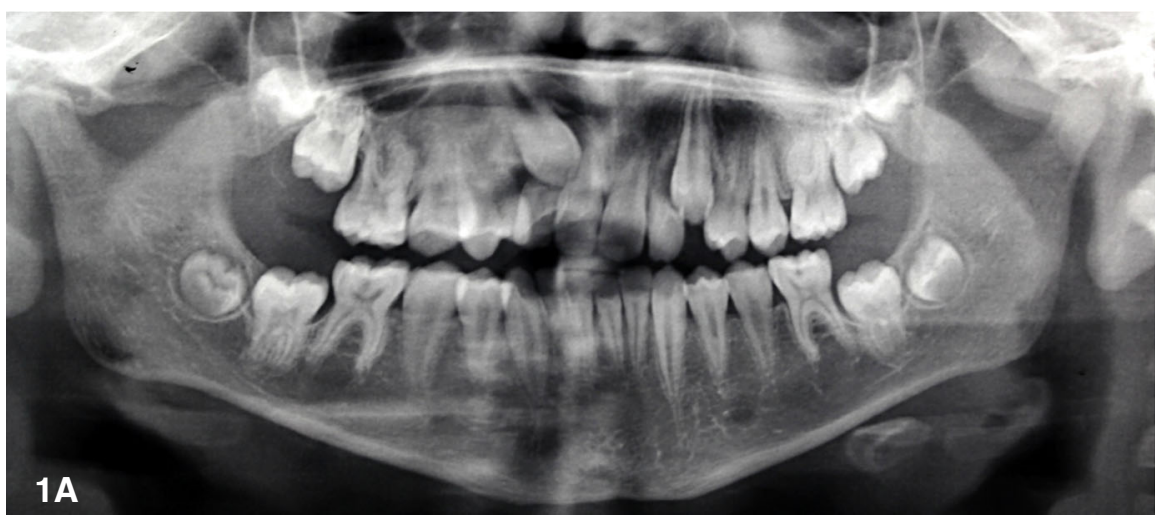




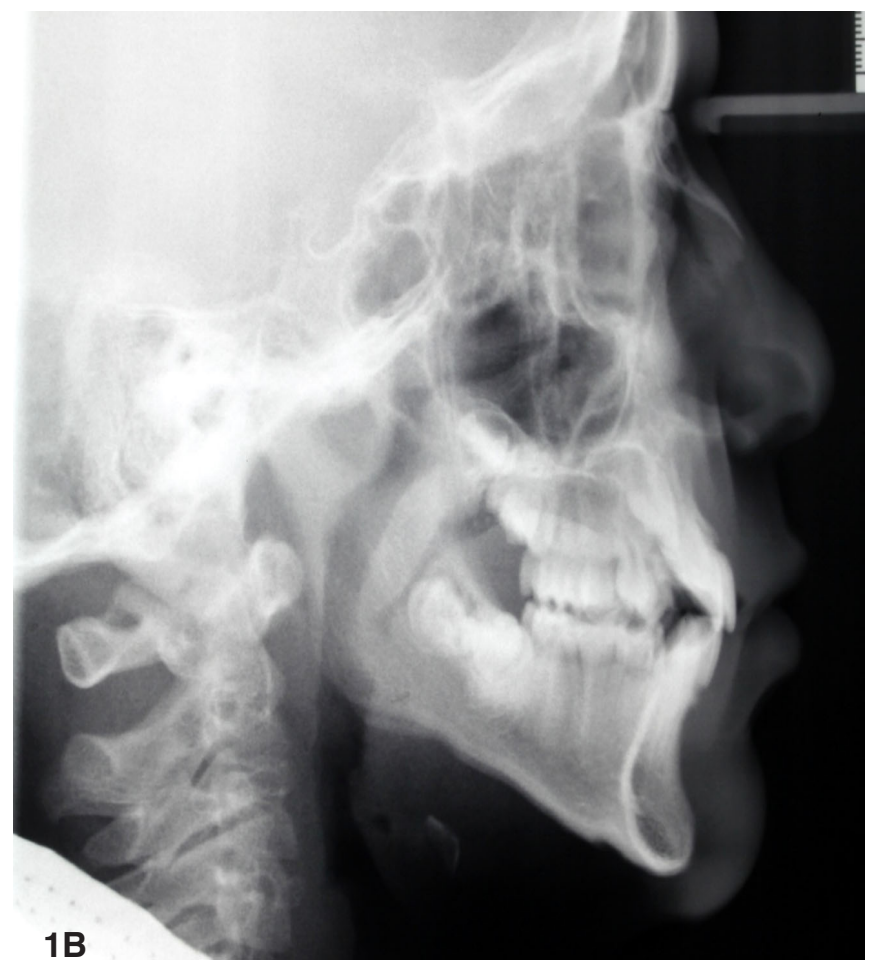

Fig. 1. Pretreatment panoramic radiograph and cephalometry

The patient is I skeletal and II dental class, hyperdivergent growth, compression in upper and lower jaw, deviation of incisive point on the right in the upper jaw. (fig.2)
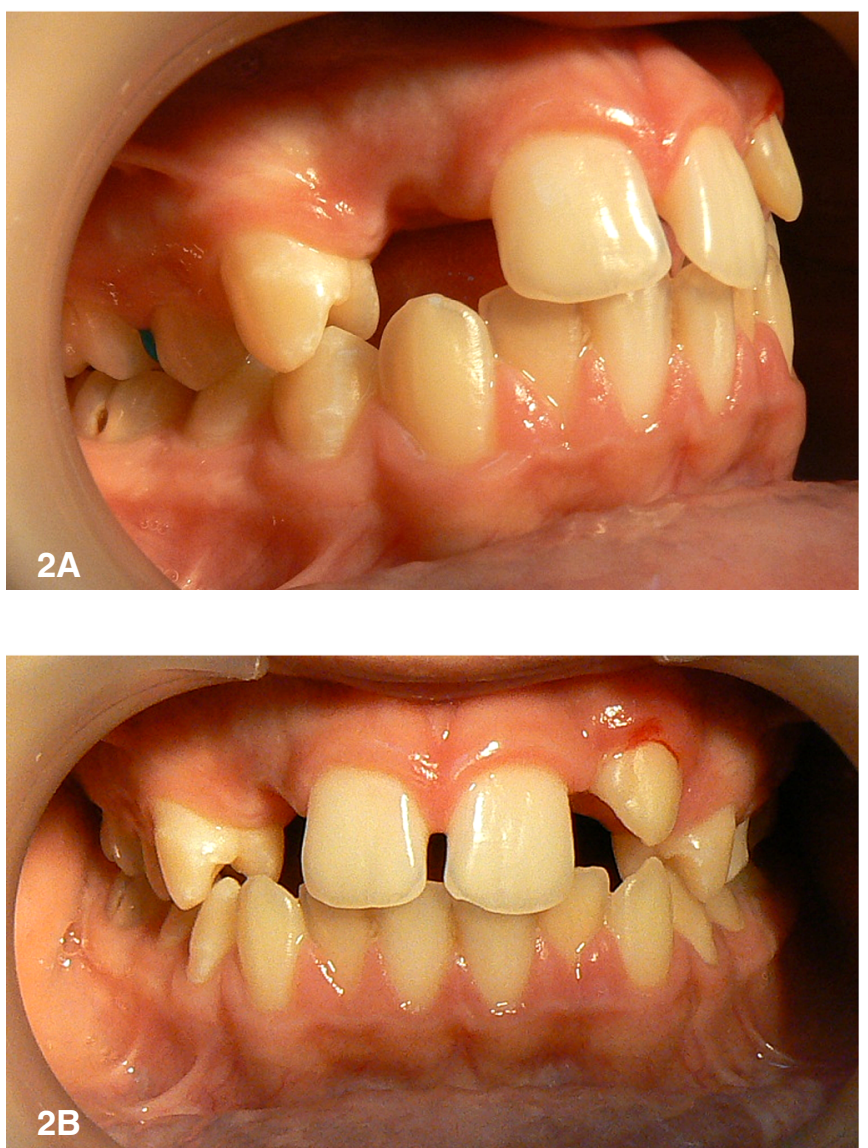
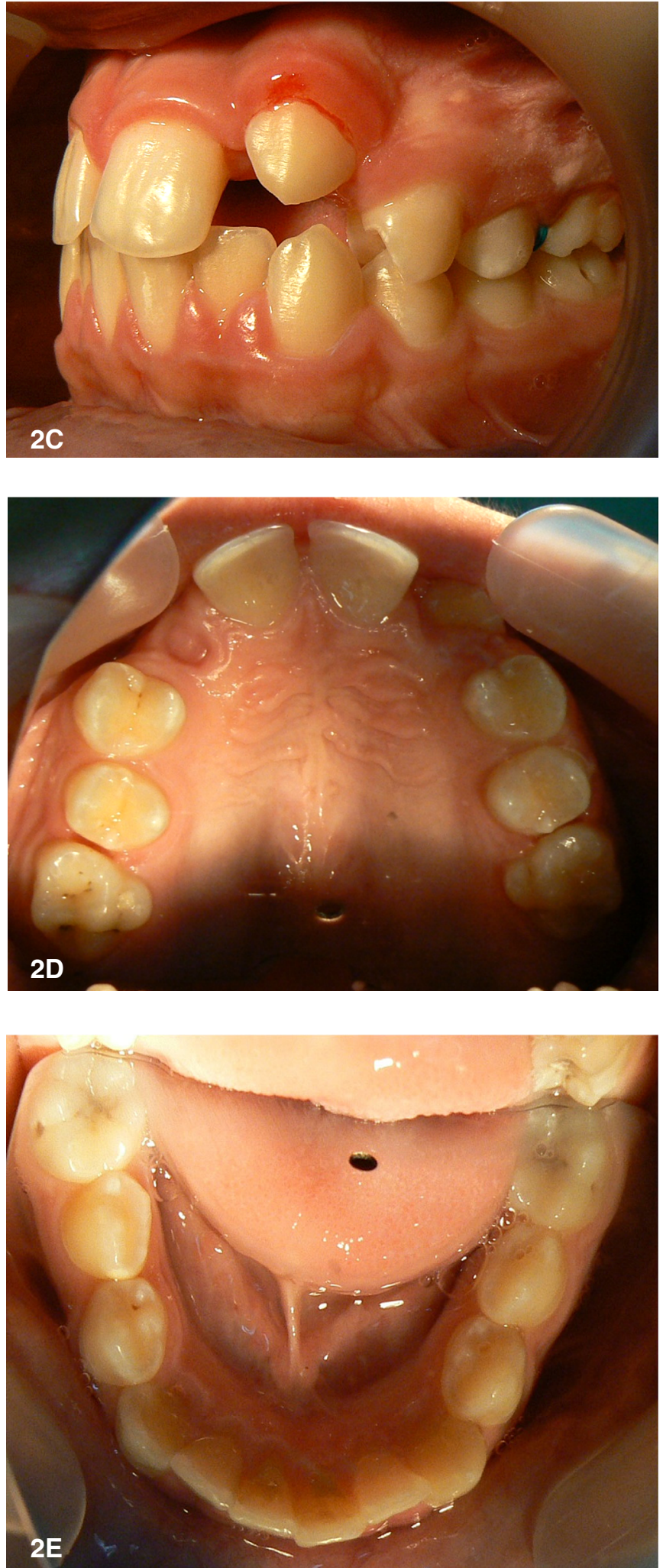

Fig. 2. Pretreatment intraoral photographs

The loss of the lateral incisors from aesthetic and functional points of view represents a complicated clinical picture. The patient's age and the complications substantiated an overall orthodontic treatment following the treatment plan below:

1. Closing the gap of the extracted lateral incisors by medialisation of the upper canines next to the central 
incisors, retrusion of the lower incisors and restoration of the normal occlusion proportions.

2. Restoring the crown of the canine using the direct bonding method with composite and modifying its form for completely refurbished aesthetic appearance in the frontal area. The lower wisdom teeth are scheduled for extraction.

\section{RESULTS:}

The treatment continued for 26 months. After the two lateral incisors were extracted, we waited for the left upper canine to erupt and then we proceeded with the shaping of the dental arch. An MBT fixed appliance system with 022 slot was used. The right central incisor was medialised in order for the diastema to be closed and for the midline to be corrected. The left canine was descended into the dental arch, while the right one, as a result of the space made available after the extraction of the lateral incisor and the medialisation of the central incisor, began to straighten its axis and to get down to the dental arch. In the lower jaw we aligned the dental arch as the space needed for aligning the front was ensured by stripping of the incisors.(fig. 3)
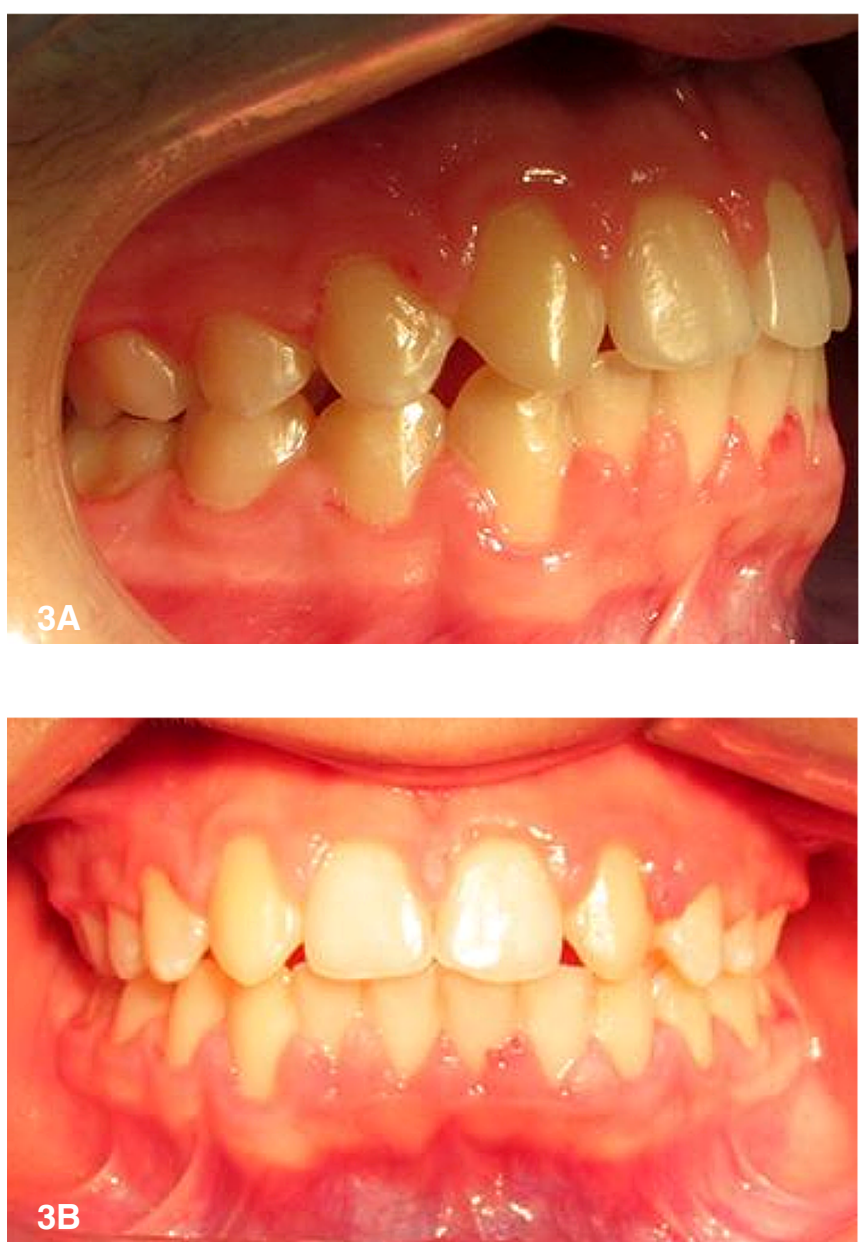
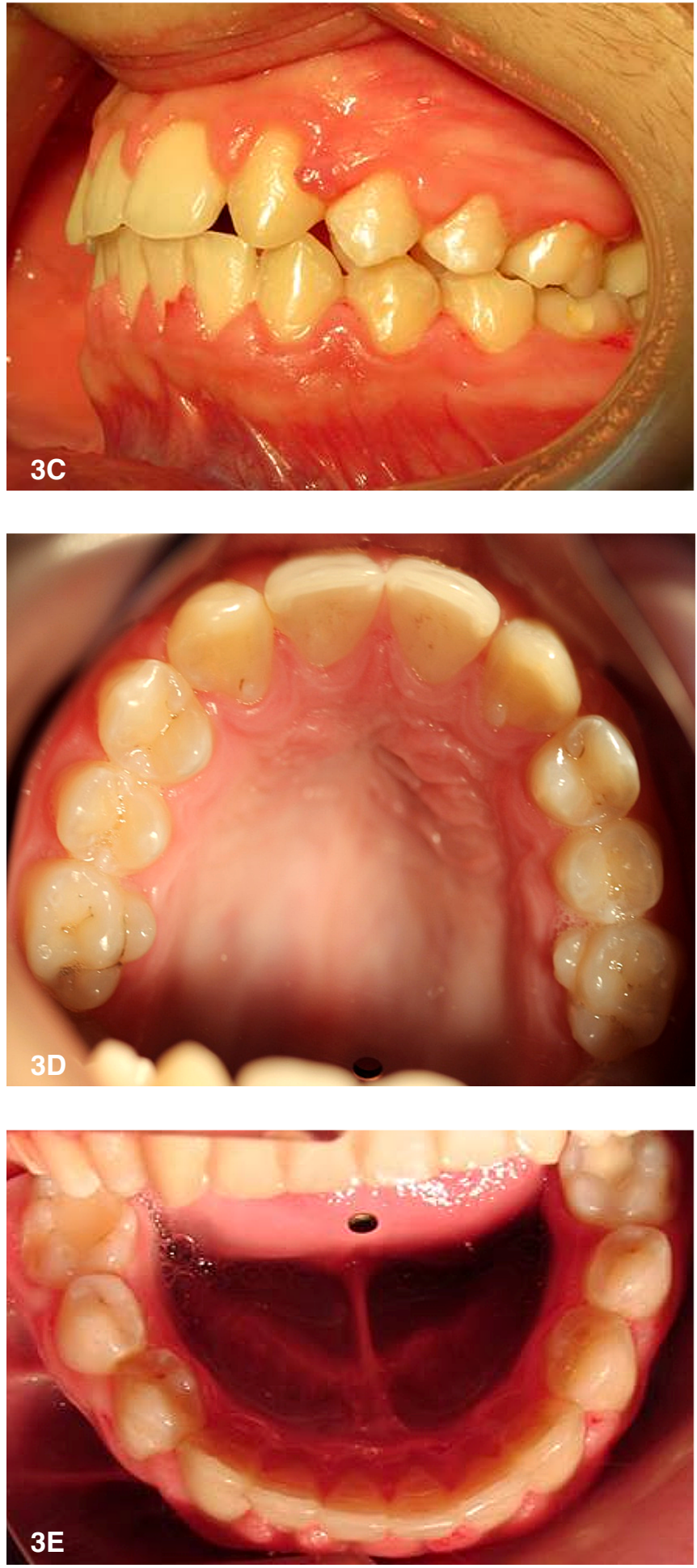

Fig. 3. Posttreatment intraoral photographs

In the result of canine impaction after orthodontic treatment, slightly root resorption of the central incisors was observed on the final OPG. This gives a poor prognosis for these teeth over the long term. (fig. 4) 

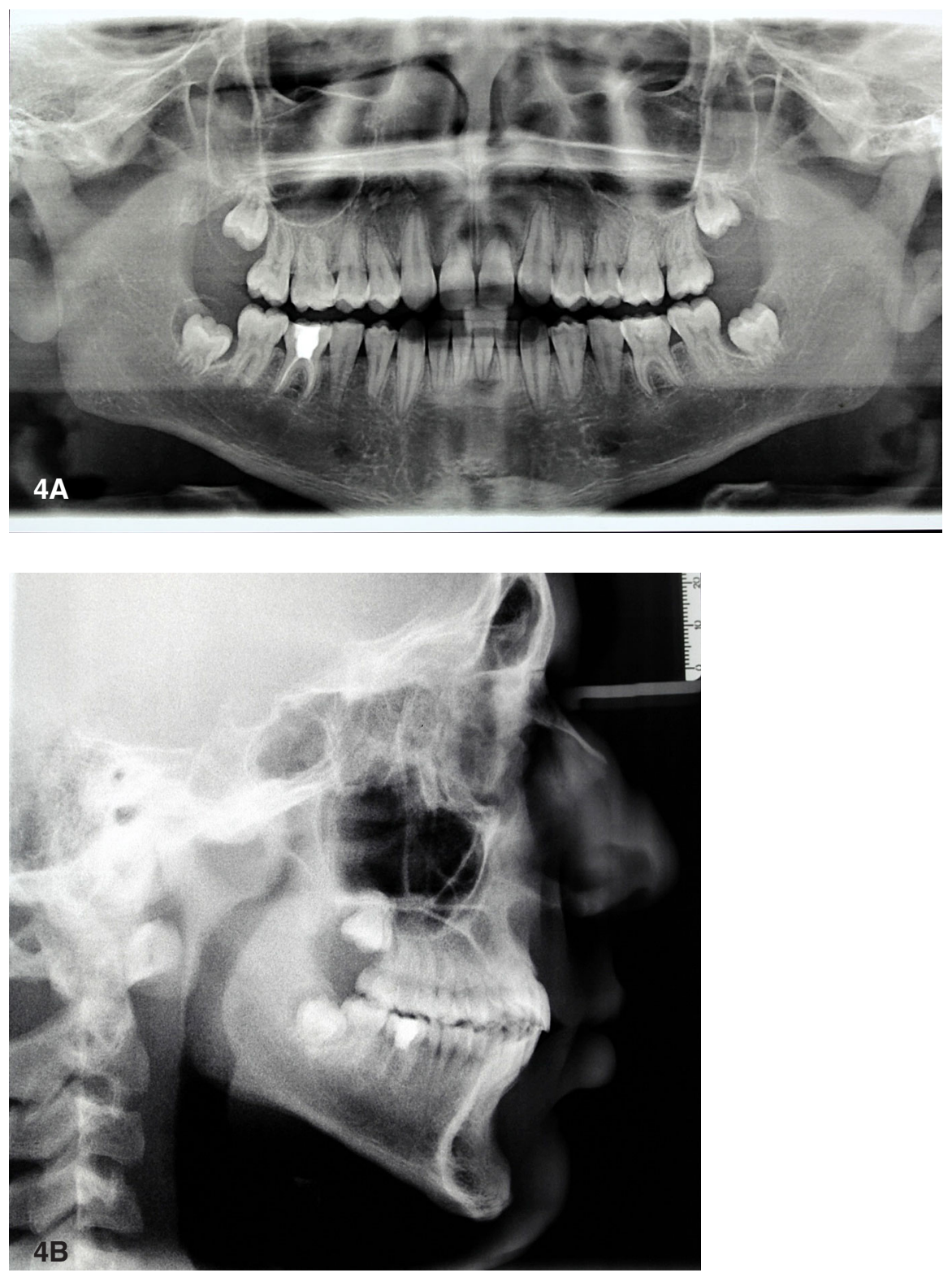

Fig. 4. Posttreatment radiographs

After the orthodontic treatment carried out, the patient is in retention phase with a removable appliance for retention. He was referred to the relevant specialists for extraction of the lower wisdom teeth and bonding of the canines for modification of their shape and improved aesthetic appearance.

\section{DISCUSSION:}

The impaction of upper canines is the second most common impaction after that of wisdom teeth. The complications due to impaction are related most often to resorption of the roots of the central and lateral incisors which are of considerable significance for the aesthetic appearance and functional life of the dentition. The resorption as complication may be foreseen and measures can be taken for its prevention. Those are related to the provision of conditions for proper eruption of the canines. The inclination of the canine and the crossing the axis of the lateral incisor medially by the tip of the canine crown

indicate canine impaction. By extracting the deciduous canine and ensuring space for the canine in the dental arch, the probability of canine eruption will be increased while the probability of the occurrence of complications related to the resorption of the adjacent teeth will be reduced.

\section{CONCLUSION:}

Timely detection in early mixed dentition and prompt preventive measures will lead to avoiding the severe complications due to impacted canines and preserving the morphological and functional integrity of the incisors. The loss of incisors seriously deteriorates the aesthetic appearance and function which requires orthodontic and complex surgical-orthodontic treatment in order to repair the dental arch and occlusion. Early prevention will provide optimal aesthetic appearance for the patient, preservation of the natural integrity of the dentition and will avoid a prolonged and expensive orthodontic treatment. 


\section{REFERENCES:}

1. Ericson S, Kurol J. Incisor resorption caused by maxillary cuspids. A radiographicstudy. Angle Orthod. 1987 Oct;57(4):332-346. [PubMed]

2. Ericson S, Kurol J. Early treatment of palatally eruptingmaxillary canines by extraction of the primary canines. Eur J Orthod. 1988 10(1):283295. [PubMed] [CrossRef]

3. Ericson S, Kurol J. Incisor root resorptions due to ectopic maxillary ca- nines imaged by computerized tomography: acomparative study in extracted teeth. Angle Orthod. 2000 Aug;70(4): 276-283. [PubMed]

4. Ericson S, Kurol J. Resorption of incisors after ectopic eruptionof maxillary canines: A CT study. Angle Orthod. 2000 Dec;70(6):415-423. [PubMed]

5. Kim Y, Hyun HK, Jang KT. The position of maxillary canine impactions and the influenced factors to adjacent root resorption in the Korean population. Eur J Orthod. 2012 Jun;34(3): 302-6. [PubMed] [CrossRef]

6. Sasakura H, Yoshida T, Murayama S, Hanada K, Nakajima T. Root resorption of upper permanent incisor caused by impacted canine. Int $J$ Oral Maxillofac Surg. 1984 Aug; 13(4):299-306. [PubMed]

\section{Address for correspondence:}

Dr. Hristina Arnautska, D.M.

Department of Prosthetic Dental Medicine and Orthodontics, Faculty of Dental Medicine - Varna,

150, Tsar Osvoboditel Blvd., Varna, Bulgaria.

Tel.: +359 888599678

E-mail: tineia@yahoo.com; 